\title{
Total Cost of Ownership in the Services Sector: A Case Study
}

AUTHORS

\section{Krisje Hurkens}

is a consultant at Significant B.V., a company providing consultancy

services on procurement and support services, The Netherlands.

Wendy van der Valk

is a Ph.D. candidate in purchasing and supply management at the

Erasmus Research Institute of Management, RSM Erasmus

University, in Rotterdam, The Netherlands.

Finn Wynstra

is the NEVI professor of purchasing and supply management at the

Erasmus Research Institute of Management, RSM Erasmus University

in Rotterdam, The Netherlands.

Few detailed studies exist of the trade-offs to be made when developing a comprehensive, strategically focused total cost of ownership (TCO) model. Moreover, most studies of TCO have been conducted in manufacturing firms, with little or no TCO research directed toward service organizations. This research presents the results of a study conducted at a leading vehicle glass repair and replacement organization.

The results show how TCO infor-

SUMMARY mation can be used for strategic decision making regarding the allocation of volumes. This information can also be used in the identification of improvement areas for preferred suppliers by introducing a limited number

The Journal of Supply Chain Management: A Global Review of Purchasing and Supply Copyright (c) February 2006, by the Institute for Supply Management, Inc. ${ }^{\mathrm{TM}}$

EXAM Q Module 1

\section{STRATEGIC APPLICATIONS OF TOTAL COST OF OWNERSHIP (TCO)}

Several trends have boosted the adoption of a strategic purchasing focus. These trends include more emphasis on the quality of purchased materials and services, supply base rationalization, and increased global competition, to name just a few, all in the light of the growing recognition of the significance of purchasing expenditures (Ellram and Siferd 1998). Purchasing decisions quite often affect a large part of a company's total costs, not only in terms of direct acquisition costs but also regarding indirect costs in the areas of inventory management, quality assurance, administration, and payment, among others. TCO is a tool that can serve to analyze these indirect costs, and is argued to be one of the important instruments in supporting a more strategic focus on purchasing and supply management (Van Weele 2005; Wouters, Anderson and Wynstra 2005).

Ellram and Siferd (1998) identify three levels of TCO analysis supporting cost management: operational, tactical, and strategic. In practice, TCO is mainly applied at the operational and tactical levels. Examples of this are TCO models developed for the purpose of managing, measuring, and improving individual suppliers. TCO can also be used to think about cost at the strategic level; as such, a TCO model could be the starting point to redesign and make the supply chain more cost efficient. However, these latter applications of TCO have received scant attention in prior research. Most of the extant literature focuses on the mechanisms of constructing a TCO model.

The current research aims to make a contribution to the literature not only by showing how a TCO model can be developed but also how such a model can be used to manage suppliers and improve the supply chain process - as opposed to merely selecting suppliers on the basis of TCO. The primary objective of the model developed in the current study is not to facilitate supplier selection, but to assist the firm in managing the ongoing performance

The authors would like to thank Ms. Kristel Hoegaerts, Business Analyst, and Mr. Raf Verheyden, Strategic Sourcing Manager Carglass Europe from Belron International, for their assistance and sponsorship of this project. 
of their supply base and making volume-allocation decisions.

To help focus these improvement efforts, key performance indicators (KPIs) were introduced in the TCO model. This represents a contribution beyond the current TCO literature, by providing an "intermediate" level of indicators that makes the relation between certain process improvements and their impact on TCO much more transparent. It also serves to delineate the respective impact that the buying organization and the supplier can have on total cost; the KPIs in the current model refer solely to supplier performance.

This paper presents the results of a case study on a company operating in the service industry. The focal company, Carglass, is a leading vehicle glass repair and replacement expert operating in the after sales or replacement market. Traditionally, TCO models have been developed predominantly to serve decision making in manufacturing companies (e.g., Degraeve and Roodhooft 1999). There is little research on the applicability of TCO in a service environment (Degraeve, Labro and Roodhooft (2004) being an exception). In recognition of the everincreasing importance of services in today's economy, this seems counterintuitive and should have spawned additional research interest in the area of TCO in service companies (Axelsson and Wynstra 2002).

The next section explains the concept of TCO and its applications. Next, the case study carried out at Carglass is presented. After a short introduction to Carglass and the glass purchasing decision under study, the research approach is discussed. The current research approach adheres to the framework developed by Degraeve and Roodhooft (2001), which serves as a conceptual umbrella for the paper. The final section addresses conclusions and implications.

\section{CONCEPT OF TCO}

TCO is a purchasing tool and philosophy aimed at understanding the relevant cost of buying a particular good or service from a supplier (Ellram and Siferd 1998). The concept takes into account all costs that the purchase and the subsequent use of components entail in the entire value chain of the company (Shank and Govindarajan 1992), and thus expands the notion of purchasing cost by combining the life cycle cost effects with the acquisition price.

The approach requires the quantification of qualitative factors into monetary terms, which enables supplier comparison not only on quantitative factors like price and delivery time but also on elements that are more difficult to measure, like quality. For example, a company that wishes to incorporate price and quality into a TCO model may wish to add to the purchase price the cost of rework on items that are below quality standards, or a cost supplement based on the actual percentage of quality defects times the cost for purchasing a replacement item. This approach incorporates all relevant costs in the model. As a result, comparisons of suppliers and their respective offerings are made on the basis of evaluation of all relevant performance characteristics on a monetary basis.

As a management-accounting-oriented purchasing approach, TCO is most often used for the supplier selection decision (Degraeve, Labro and Roodhooft 2000; Degraeve and Roodhooft 2000). However, it could also be used to evaluate a supplier's performance in an attempt to enhance the value delivered to the buying organization (Carr and Ittner 1992). Other uses of the cost method include the assessment of the purchasing department itself (Degraeve and Roodhooft 1999), and supporting negotiations with suppliers and volume allocation among suppliers (Ellram 1993).

The actual scope of TCO may differ across firms and products. A process flow diagram can be drawn up to determine where activities of suppliers take place and then categorize these activities according to some relevant, purchasing-related dimensions. Activities related to purchasing can be divided into pre-transition, transaction, and post-transaction elements. Alternatively, one can use the division by Ellram and Siferd (1998), which breaks down the purchasing activities into six categories: management, quality, price, communications, service, and delivery.

To develop an understanding of total costs, alternative approaches can be used. The first method is known as the monetary-based method, which allocates the costs of purchasing an offering (good or service) to the different cost components based on true costs. Calculations could be based on activity-based costing (ABC), which explicitly uses the activities that drive costs to assign (overhead) costs to items. ${ }^{1}$ The monetary-based method is timeconsuming, but also precise and relatively easy to interpret.

Another approach is the cost-ratio or value-based method (Carr and Ittner 1992; Ellram 1995). The valuebased method combines monetary with qualitative performance information, which is more difficult to express in monetary terms. On the basis of non-monetary, historical information, for instance supplier-rating scores of several suppliers, a total cost factor is calculated (Wynstra and Hurkens 2005).

As a third method, Degraeve and Roodhooft (2000) propose a mathematical programming decision model that can be formulated for supplier selection and order quantity determination. This method is far more

\footnotetext{
${ }^{1}$ A company does not necessarily need to have an ABC system in place before a TCO model can be implemented, although it may ease the data-gathering process.
} 
quantitatively sophisticated, but offers insights into both supplier selection and order quantity determination.

In the current case study, the monetary-based approach is used in combination with the framework proposed by Degraeve and Roodhooft (2001). In their framework, Degraeve and Roodhooft combine the steps in the procurement value chain with three levels at which costs could be aggregated. During the purchasing process, costs could be incurred during acquisition, receipt, possession, utilization and elimination. Purchasing activities are divided into three hierarchical levels: supplier-level activities, ordering-level activities, and unit-level activities. These levels are subsequently used to assign costs.

The main reason for opting for a more complicated, monetary-based method is because of the fact that glass purchases are the single most important purchase category at Carglass. Given the purchase volume involved, it makes sense to invest in a detailed, more precise method, as opposed to a more simple value-based method (Ellram 1995; Wynstra and Hurkens 2005).

\section{IMPLEMENTATION OF TCO ANALYSIS}

Despite its conceptual attractiveness, TCO analysis does not seem to be applied very widely. A recent study investigated the application of techniques such as TCO and value analysis in Dutch companies. ${ }^{2}$ The study was aimed specifically at the purchase of MRO items, such as electro motors for the production process, but also contained questions on the subject of TCO in general (Wouters, Anderson and Wynstra 2005). The study revealed that many purchasing managers have little experience in applying TCO and/or value analysis. Interviews with purchasing managers at a number of Dutch companies also showed that on the one hand TCO calculations are seen as a very relevant method for the purchasing process, but on the other they are used explicitly and elaborately only in a few cases (Wynstra and Hurkens 2005).

The major barrier to TCO implementation seems to be the lack of readily available data. The data used in the TCO model need to be specified at a very detailed level and these data are often very hard to gather in an organization. Other barriers for implementation are cultural issues that relate to general resistance to change, issues related to educating and training people in the firm, including the purchasing function, to overcome misconceptions about TCO and resource allocation (Ellram 1994).

These barriers could be overcome by following certain steps in TCO implementation. Using structural equations modeling to analyze the results of a survey among 310

\footnotetext{
${ }^{2}$ Value analysis is a concept that is often used for products that are in the engineering phase. Especially regarding the maintenance and service costs, TCO and value analysis are aimed the same aspects.
}

purchasing decision makers, Wouters, Anderson and Wynstra (2005) found evidence that top management and functional management support are important mechanisms to implement TCO-based purchasing decision making (as opposed to a primarily price-oriented decision process).

However, in order to achieve the top management support required for specifically implementing TCObased decision tools, the purchasing function must first show a clear commitment to a more strategic orientation toward purchasing and supply management. The subsequent steps to actual TCO implementation include building experience with the analysis of cost and performance of purchase items in an effort to improve information quality, gaining some initial successes with using TCO as a basis for purchasing decisions, and only then implementing some form of TCO-based performance review and reward system (Wouters, Anderson and Wynstra 2005).

As will be described in the following section, top and functional management support for the development and implementation of a TCO analysis tool is quite strong at Carglass, which definitely enhanced the implementation process. This support was because of the sense of urgency caused by an analysis of some current problems in the supply management process.

The next section focuses on developing a TCO model, which enhances Carglass' capability to better understand the total costs associated with acquiring their most important purchase item, glass (i.e., car windows). Traditional TCO studies have been mainly carried out at manufacturing companies (i.e., Degraeve and Roodhooft 1999). In contrast, the current study took place at a service company. The model helps Carglass identify and prioritize certain process improvement options with suppliers. Moreover, the model provides Carglass with insights into the consequences of changing the volume allocation among preferred suppliers. TCO analysis enables the firm to make an explicit trade-off in determining the allocation percentages.

\section{DEVELOPMENT OF A TCO MODEL AT CARGLASS}

Carglass, part of Belron International, is a leading vehicle glass repair and replacement expert operating in the after-sales market, with locations in a number of European countries. Carglass' assortment comprises windscreens (WS), body glass ${ }^{3}$ (BG) and rear screens (RS) for any brand and/or type of car. The windows are mainly passenger car windows, but also includes some coach and truck windows as part of the assortment. These windows are purchased from seven suppliers from around the world, which have earned the distinction of being

\footnotetext{
${ }^{3}$ Body glass windows are located on the sides of a car.
} 
preferred suppliers. Two suppliers (later referred to as A and B) make up the larger part of Carglass' glass purchases.

The suppliers deliver the purchased glass to any Carglass distribution center in Europe (seven in total). From these points, glass is delivered to service centers, which service clients with damaged car windows from points-of-sales located throughout the countries in which Carglass is represented. An order, which is placed during the day, is delivered to the service center the next morning. These service centers carry out the actual replacement activities for a specific client.

Traditionally, Carglass made their purchase decisions based on purchase price only. However, quality and delivery performance problems prompted Carglass to initiate supply chain analyses on a regular basis. These analyses indicated considerable additional costs incurred because of poor delivery performance, low glass quality, and related issues. For example, poor delivery performance in some cases resulted in rush deliveries, thereby incurring additional costs for Carglass. If Carglass is unable to carry out a rush delivery, the service center will be short of a screen. As a result, the service center has to buy the screen from a car dealer, which is more expensive, or else the client cannot be served.

Carglass discussed the results of these analyses with their board of directors. As a result, the board directed Purchasing to broaden the supplier selection process to go beyond price considerations. It was decided that TCO should be the starting point for this new approach to purchasing decision making. TCO also became part of a continuous improvement initiative focused ultimately on reducing the total supply chain costs.

\section{METHODOLOGY}

The aim of the project was to build a spreadsheet-based tool for calculating the TCO for glass purchases. Carglass distribution (Hasselt Distribution Center), which supplies service centers in Belgium, the Netherlands, the north of France, and Nord-Rhein Westfalen, was identified by Carglass to serve as a test case for the development of the model. The tool should support purchasing and supply chain process improvements and annual supplier selections and negotiations. Supplier selection in this case does not refer to the actual "recruitment" of a supplier, but to the allocation of the total purchase spend among the seven existing main suppliers. A well-performing supplier will thus obtain a larger part of Carglass' business, up to a certain maximum share.

The initial objective was to implement a TCO management approach for Carglass' total value chain (from supplier to client). Later in the research it was decided to limit the study to an analysis of the stages from supplier to the distribution center (DC). This resulted from preliminary investigations that indicated that the process from the DC to the service centers was relatively simple in terms of logistical and administrative processes, and showed very little variation among the different suppliers. Furthermore, the majority of the costs associated with supplier performance will be incurred in the trajectory supplier-DC. The problems related to supplier performance are solved mostly in isolation from the service center. While based primarily on the situation in Belgium, the tool should be generalizable to other DCs.

First, a business process analysis was carried out to identify all relevant physical and administrative processes associated with purchasing vehicle glass from suppliers and getting this glass delivered to the DC. This analysis was performed in close collaboration with a Carglass business analyst.

A cost driver and rate analysis was subsequently carried out to determine the relevant cost drivers for allocating costs and their rates. This was done by studying the actual administrative and physical handling processes, among others, through interviews with managers and employees from different departments involved and in situ time studies of the various activities. For financial and other performance data, various Carglass systems, databases, and reports were analyzed, such as the supplier rating and the ERP system. A preliminary model was developed, which included calculations of TCO values. This model was presented to and discussed with Carglass on a number of occasions, after which it was revised. The final model is presented in the current research.

\section{ANALYSIS}

This section presents the results of the process analysis, after which the relevant cost drivers and the associated rates are determined. Only the major cost components (i.e., the components that result in large differences in costs between suppliers) were included. These drivers could be at the unit level (e.g., material cost per unit), the order level (e.g., cost of an inspection), or the supplier level (e.g., cost of identification and certification of a supplier). This approach to designing the TCO model closely resembles the method proposed by Degraeve and Roodhooft (2001). However, their process terminology (acquisition, reception, etc.) has been translated into the terms used by Carglass.

\section{Mapping the Relevant Business Processes}

Carglass' supply chain performance report was used as a point of departure for gathering information regarding the glass supply process and the factors impacting costs. Gaps were filled and ambiguities were resolved by consulting the strategic sourcing manager, who was the project leader on behalf of Carglass, and the business analyst, who was responsible for carrying out the supply chain analyses. The life cycle of a window was taken as a starting point for identification of a 




Legend:


Processes outside project scope

Range

number of processes, both physical and administrative. An overview of these processes is given in Figure 1.

It should be emphasized that physical processes are not the only relevant aspect for the TCO model. Many physical flows have to be supported by administrative processes, including supplier monitoring and administration. Although not all of these activities are shown explicitly in Figure 1, these processes are also incorporated into the TCO model, for example, the extra time per window needed for administering a dealer window. Other supporting processes like acquiring human resources only have an indirect link with the physical flow of a window. Therefore, these latter processes are excluded from the TCO model.

Carglass' main activities comprise ordering and receiving car windows from preferred suppliers and, after the quality has been checked, transferring these windows to the service centers. Surplus windows may either be put on stock in the warehouse or returned to the supplier. Quality defects are returned to the supplier. If a window cannot be delivered by preferred suppliers, because of poor delivery or low-quality performance, Carglass has to buy from dealers (adverse buy). Buying from dealers can also occur as a result of the introduction of new windows by a car manufacturer, while the suppliers have no "copy" of the new window available (dealer buy). ${ }^{4}$ The preferred suppliers will try to develop copies of these new windows as soon as possible; when they do, a quality confirmation is required before Carglass orders windows from preferred suppliers. This whole process is constantly monitored by Carglass.

These activities and their respective cost categories are discussed in more detail hereafter.

\section{Cost Categories}

The life cycle begins with a newly introduced window as part of a new car brand and/or type. In this case, Carglass' suppliers are not yet able to manufacture this window. In order to serve clients with this new car, Carglass has

\footnotetext{
${ }^{4}$ Dealer buy and adverse buy thus refer to the same processes, but differ with regard to their causes. Dealer buy occurs because the preferred suppliers have not yet produced the new window (the buy is inevitable), whereas an adverse buy is caused by low performance (the buy is undesirable).
} 
to purchase original windows from a dealer, which is referred to as "dealer buy."

The next phase is "quality." Newly introduced windows are "copied" by Carglass' suppliers as soon as possible.

Before a "copied" window is included in Carglass' assortment, a quality confirmation check is performed to ensure that the copied window fits the car and that lifecycle quality is according to standards. In most cases, the supplier performs this confirmation check, but for one supplier Carglass does its own verification. ${ }^{5}$

When windows have been delivered to the DC, either by the regular suppliers or by dealers, an inbound "quality check" is carried out. This is done by means of a random sample check (e.g., check window no. 1, 7, 9, 13 and 19 from four of the 20 crates received). If a window, or an entire crate in case of a bad production run, is rejected, it is returned to the supplier. If windows that are directly needed by the service center are rejected, Carglass has to obtain these windows from dealers ("adverse buy").

Windows that have quality defects or that were delivered without being ordered are returned to the supplier ("supplier returns"). These windows are collected in separate crates for each supplier. These crates are returned once a month. One of the suppliers first sends a representative to approve the return shipment; returns that are not accepted by this representative cannot be sent back to the supplier. Furthermore, damaged windows are not always refunded.

If there is a difference between what was ordered and what was actually delivered, a decision has to be made. When what was ordered exceeds delivery, Carglass has to perform an adverse buy. This means that even though the regular suppliers can supply that particular window, the window still has to be bought from a dealer because of insufficient delivery.

When the delivery exceeds what was ordered, another decision has to be made. Carglass can either choose to put the surplus on stock (which is usually done when it concerns windows that are sold regularly) or to return the surplus to the supplier with the supplier taking care of the return transport.

After a window has been accepted, it enters the "warehousing" stage, which results in "handling," "inventory holding," and "storing" costs.

The windows that are accepted are moved into the warehouse in a "handling" operation. The packages that the supplier uses impact the amount of handling needed in the warehouse. The costs associated with this issue are substantial. Indirectly, the amount of dealer buy increases the warehousing cost, because of the fact that dealer windows are wrapped separately and thus take more time to unpack than the crates of the regular suppliers that hold a dozen windows each.

Two people are employed to unpack delivered goods. One of them is assigned to unpack the supplier windows, and the other to unpack dealer windows. They both work full time on this job. However, the dealer-windowunpacker handles some 100,000 windows a year while the supplier-window-unpacker handles a number close to 1,000,000. Furthermore, minor variations exist with regard to the number of windows preferred suppliers pack per crate; the more the windows per crate, the less the handling time per window.

Regarding the inventory holding costs, forecasts are made for the coming period based on sales in the service centers. This forecast is then ordered from suppliers, upon which delivery takes place. Inventory can therefore exist because of two reasons: (1) there is a difference between the forecast of sales and what is actually being sold; and (2) there is a difference between what is ordered from the supplier and what is actually delivered by that supplier. As the model aims to highlight extra cost because of supplier behavior, only the second reason was taken into account as a cause of inventory holding cost.

Once the windows have arrived in the warehouse itself, "storing" costs are mainly affected by the actual volumes of windows.

Throughout these processes, suppliers have to be monitored ("supplier monitoring"). Three people are involved in monitoring and analyzing suppliers' performance and in resolving any issues that arise.

Finally, the TCO of the different suppliers is affected by their payment terms ("cash flow").

As the model was to be used for negotiating prices and initiating improvement actions, it was important for Carglass to be able to monitor the whole supply process, and not just the problems caused by suppliers. Therefore, the researchers adopted a process focus instead of a problem focus. Whereas a problem focus would only take into account costs because of low performance of the supplier or specific circumstances, a process focus assists Carglass gain insights into the balance between regular process costs and costs because of problems (a high supplier performance could still result in substantive process costs). This information can then be used in the negotiation process to distinguish between suppliers clearly. For example, the process focus also includes the calculation of TCO effects of payment terms. Although current suppliers have identical terms, Carglass wishes to be able to investigate the impact that changes in payment terms would have on TCO.
${ }^{5}$ Carglass does not rely on the quality system of the supplier because this system does not conform to European standards. 


\section{Identifying Relevant KPIs}

All cost categories can be related to factors that drive these costs. For instance, the cost category "dealer buy" is strongly influenced by the factor time-to-market, as the longer it takes the supplier to copy a newly introduced window, the more Carglass has to resort to dealers for these windows. This factor could be regarded as a KPI, based on which Carglass can monitor ongoing performance, preferably with the help of their suppliers.

This case study attempted to identify KPIs for all costincurring activities. After initial identification of the costs at the supplier, order, and unit levels, the supplierinduced costs were separated explicitly from the other costs. Only supplier-induced costs are taken into account as these costs are influenced by the actions of the suppliers. These actions are linked to costs with the KPIs. As a result, costs are not only measured, but a tool is developed that allows for actively managing costs and thinking about redesigning the process so that costs can be eliminated structurally.

Discussions with Carglass employees provided the researchers with considerable insights into the extent to which Carglass had to buy glass from car dealers, impacting the glass spend. Mapping the processes unveiled the extent to which Carglass' forced purchases from car dealers are directly related to supplier performance in multiple ways.

In the situation where the supplier has not yet copied a newly introduced window, Carglass has to buy from a car dealer (dealer buy), which is more expensive. The longer the supplier needs to copy a newly introduced window, the more the dealer buys for Carglass. Thus, the supplier's time-to-market is the driving factor (KPI) here.

In the second situation, where the supplier does not deliver on time or does not deliver what was ordered, Carglass has to buy from a car dealer (adverse buy), thereby again incurring extra costs. The larger the difference between what should be delivered and what was actually delivered, the larger the adverse buy. The driving factor is delivery performance.

The final situation, where the supplier delivers glass of poor quality, also results in an adverse buy. The larger the number of rejects, the larger the adverse buy. The driving factor here is quality performance.

Therefore, the larger part of the costs is dependent on three important factors (KPIs): time-to-market, delivery performance, and quality performance. In addition to this, extra costs are incurred as a result of the payment terms. A difference in payment terms, for example, of five days can result in substantial cost savings. This is a fourth important driving factor.

Finally, some other, somewhat smaller cost categories can be distinguished. The supplier's delivery performance determines the cycle stock and the safety stock. More inventory holding costs are incurred when the stock levels are higher. Interestingly, the costs in this category are small in comparison with the four categories mentioned above.

As discussed, the packages that the supplier uses also have an impact on the amount of handling needed in the warehouse. Finally, a large number of quality defects will result in a higher number of supplier returns.

Whether or not the supplier reimburses these rejects can contribute to substantial costs as well. In the current situation, rejects are not reimbursed by any of the suppliers. The representative sent to Carglass by one of the suppliers to check whether the supplier should accept the returns or not comes from abroad and visits once every 2 months. The other suppliers ship returns monthly. Handling of supplier returns obviously involves some labor costs too, but their magnitude is negligible in comparison with the costs discussed earlier.

For each of the different cost categories identified, Table I lists the KPIs that impact these costs.

\section{Determining Cost Formulas}

Cost calculations were developed for the different cost categories mentioned earlier. The data needed to perform the calculations were drawn from Carglass' supplier rating, ERP, and accounting systems. For some categories, it was harder to gather data than for others, as data were available at varying levels of detail.

The costs for each cost category were calculated on a separate sheet, making it easy to link the costs to a specific

Table I

COST CATEGORIES AND KEY PERFORMANCE INDICATORS

\begin{tabular}{ll} 
Cost Categories & Key Performance Indicators \\
\hline Dealer buy & Average time-to-market \\
Quality confirmation & $\begin{array}{l}\text { Number of checks necessary to } \\
\text { approve new window }\end{array}$ \\
Quality check & Quality performance \\
Supplier returns & Quality performance \\
& Delivery performance \\
& Refund rate \\
Adverse buy & Delivery performance \\
Warehousing & Quality performance \\
Handling & \\
Inventory holding & Average \# of windows/crate \\
Storing & Average leadtime \\
Supplier monitoring & Standard deviation lead time \\
Cash flow & Purchase volume \\
\hline
\end{tabular}


category. The suppliers, in one way or another, can influence all cost drivers. These cost drivers or KPIs enable Carglass to determine in what way and to which extent a change in supplier performance affects the associated costs. In Appendix A, one can find the complete specifications of the cost formulas, including the KPIs.

\section{RESULTS}

The following sections present the results of the case study. The model is presented, after which its use is elaborated.

\section{Final TCO Model}

The final model has been developed in a spreadsheet (Microsoft Excel). The spreadsheet consists of a series of calculations for the different processes identified as being important. Most of the sheets are interlinked, providing an easy reference to the underlying calculations. Figure 2 provides an illustration of how the TCO per supplier is broken down into individual cost components.

The spreadsheet works based on a central sheet, in which the general data can be put, as well as on a separate KPI sheet. The KPI sheet contains factors contributing to high costs, such as time-to-market, delivery performance, quality performance, and payment terms. Furthermore, the spreadsheet highlights graphical overviews of the cost structures per supplier, both in absolute and relative numbers. Finally, the spreadsheet presents an overview of the relative TCO performance per cost category/ process. The best performing supplier is set at 1 , while the others are valued relative to the best performer.

\section{Use of the Model}

The spreadsheet can be used to compare suppliers on different cost categories/processes. The information obtained from this comparison can be used to allocate the glass portfolio to suppliers, including which car brand/ type windows to obtain from which supplier, or to discuss areas for improvement with suppliers and to negotiate glass prices. The KPIs provide the opportunity to carry out sensitivity analyses, so that Carglass can set targets before entering negotiations. The model thus provides insights into the consequences of changing the volume allocation among preferred suppliers, which allows Carglass to make an explicit trade-off in determining the allocation percentages.

Carglass is using the TCO model in different ways. Between August 2003 and March 2004, the responsible purchasing manager had conducted an extensive internal "roadshow" to demonstrate the model and create awareness among the different buyers and other functions across Europe. Based on feedback from various sources, minor modifications have been made in the grouping of cost categories and the user interface. In 2004, the tool was used to guide and monitor two strategic drivers for

\section{Figure 2}

\section{SCREENSHOT OF TCO OVERVIEW WITH FICTIONAL DATA}




supplier improvement: reduction of time-to-market and the reduction of stocks. Incidentally, it has already been used in discussions with individual suppliers to explain volume shifts toward other suppliers, trigger process improvements and, to a lesser extent, negotiate price reductions. The data needed to update the TCO model were then integrated into the monthly supply management reports in order to monitor cost savings.

\section{CONCLUSIONS AND IMPLICATIONS}

The fact that the spreadsheet has already been partially adopted and developed further proves its added value to Carglass. Even the gathering of data, which is usually a large barrier to the development of TCO models, was relatively easily overcome because Carglass assigned a business analyst to the project. Furthermore, the resistance to change was low within the organization as Carglass initiated this project to assist in overcoming some of the challenges associated with short- and longterm financial consequences of variations in supplier performance.

This paper shows that TCO can be a useful tool to uncover the obvious as well as the hidden costs of conducting business with different suppliers. This does not only hold true for use in supplier selection but also in negotiation rounds. While Carglass does not wish to choose among its suppliers, it does wish to be able to shift volume between them when necessary. Admittedly, the calculated rates may not provide a complete picture of costs; they do offer an estimate of the relative magnitude of the different cost categories. In the negotiation rounds, Carglass can now focus on the cost savings that are concealed in the contractual terms, which affords opportunities for both Carglass and suppliers to improve their businesses.

Examples of these are shifting quality confirmation activities to the supplier and investigating the option of committing adverse buys with non-preferred suppliers instead of dealers. Additionally, Carglass can now more thoroughly realize the enormous impact that differences in payment terms have on TCO. This particular finding has specific and immediate usefulness in negotiating. Occasionally, a supplier has lower costs of capital than the customer and thus may be more interested in extending payment terms rather than giving price reductions. In general, one could argue that using TCO analyses in supplier negotiation increases the number of variables on which to negotiate, thereby increasing the possibilities of a "win-win" solution.

This paper has also demonstrated that in the case of a monetary-based TCO model, it is crucial to develop an accurate, precise, and complete representation of the physical and administrative processes in the pretransaction, transaction, and post-transaction phases of the purchasing process. Even though the processes at
Carglass are relatively straightforward and lack complex production processes, this process analysis is quite time consuming.

The identification of KPIs and explicit connection of these indicators to the different categories of costs is a relatively novel feature of this type of analysis. The indicators as such were not new to Carglass, which makes it easier for purchasing decision makers to adopt and embrace the TCO analysis model. At the same time, linking the indicators to cost calculations and demonstrating the actual financial effects of certain performance variations on different indicators serve to make the tradeoffs between improving on one indicator versus the other more transparent.

Furthermore, it has been a conscious decision to develop KPIs that can be explicitly linked to the supplier's performance. Improving the performance of the total supply chain requires improvements in the performance of all the parties involved, including Carglass. Carglass' objectives have been translated into KPIs, and subsequently these KPIs are the starting point for developing KPIs for the supplier by investigating how the supplier can contribute to total performance improvement.

Obviously, there are opportunities for model enhancement and refinement. An important limitation of this study lies in the level of aggregation. Even though Carglass' management system contains detailed information on item level, the time span of this project was too short to develop the model at this level of detail. The model therefore only provides calculations of the total costs incurred per supplier, for the different items combined (front, side and rear windows).

In addition, not all costs associated with the supply of windows are incorporated into the model, as discussed earlier. Admittedly, doing this would result in a more accurate model. However, the initial experiences demonstrate that in its current form the tool creates sufficient understanding of the factors impacting the TCO of car windows, thereby providing Carglass with actionable information with which to manage their suppliers and to improve their overall purchasing and supply management processes.

\section{References}

Axelsson, B. and F. Wynstra. Buying Business Services, Wiley, Chichester, 2002.

Carr, L.P. and C.D. Ittner. "Measuring the Cost of Ownership," Journal of Cost Management, (6:3), 1992, pp. 42-51.

Degraeve, Z., E. Labro and F. Roodhooft. "An Evaluation of Vendor Selection Model from a Total Cost of Ownership Perspective," European Journal of Operational Research, (125:1), 2000, pp. 34-58.

Degraeve, Z., E. Labro and F. Roodhooft. "Total Cost of Ownership Purchasing of a Service: The Case of Airline Selection at Alcatel Bell," European Journal of Operational Research, (156:1), 2004, pp. 23-40. 
Degraeve, Z. and F. Roodhooft. "Improving the Efficiency of the Purchasing Process Using Total Cost of Ownership Information: The Case of Heating Electrodes at Cockerill Sambre S.A.," European Journal of Operational Research, (112), 1999, pp. 42-53. Degraeve, Z. and F. Roodhooft. "A Mathematical Programming Approach for Procurement Using Activity Based Costing," Journal of Business Finance and Accounting, (27:1/2), 2000, pp. 69-98.

Degraeve, Z. and F. Roodhooft. "A Smarter Way to Buy," Harvard Business Review, (112/1), 2001, pp. 22-23.

Ellram, L.M. "A Framework for Total Cost of Ownership," The International Journal of Logistics Management, (4:2), 1993, pp. 46-60.

Ellram, L.M. "A Taxonomy of Total Cost of Ownership Model," Journal of Business Logistics, (15:1), 1994, pp. 171-191.

Ellram, L.M. "Total Cost of Ownership: An Analysis Approach for Purchasing," International Journal of Physical Distribution and Logistics Management, (25:8), 1995, pp. 4-23.
Ellram, L.M. and S.P. Siferd. "Total Cost of Ownership: A Key Concept in Strategic Cost Management Decisions," Journal of Business Logistics, (19:1), 1998, pp. 55-84.

Shank, J.K. and V. Govindarajan. "Strategic Cost Management: The Value Chain Perspective," Journal of Management Accounting Research, (4:Fall), 1992, pp. 179-199.

Van Weele, A.J. Purchasing and Supply Chain Management Analysis, Strategy, Planning and Practice, 4th ed., Thomson Learning, London, 2005.

Wouters, M.J.F., J.C. Anderson and F. Wynstra. "The Adoption of Total Cost of Ownership for Sourcing Decisions - A

Structural Equations Analysis," Accounting, Organizations and Society, (30:2), 2005, pp. 167-191.

Wynstra, F. and K. Hurkens. "Total Cost and Total Value of Ownership." In M. Essig (Ed.), Perspektiven des Supply Management: Konzepte und Anwendungen, Heidelberg, Springer, 2005, pp. 463-482.

\section{APPENDIX A: COST FORMULAS}

\section{- Dealer buy}

- TTM factor $=\{$ Time-to-market $\} \times\{$ Number of windows $\} \times\{$ Share of purchase spend $\}$.

- Dealer buy because of new window $=\{$ Annual purchase volume dealer $\} \times\{$ Percentage dealer buy because of new window\}.

- Dealer spend supplier $=\{$ TTM factor $\} /\{\Sigma($ TTM factor $)\} \times\{$ Dealer buy because of new window $\} \times\{$ Purchase price preferred/non-preferred/dealer - Purchase price preferred supplier\}. ${ }^{6}$

- Quality confirmation

- Labor cost of quality confirmation $=\{$ Number of people assigned to quality confirmation $\} \times\{$ Labor cost $\} \times$ \{Percentage of labor spent on quality confirmation\}.

- Quality confirmation cost per supplier $=\{\text { Number of checks necessary to accept a new window }\}^{7} \times\{$ Labor cost of quality confirmation\}.

- Quality check

- Labor cost of sample check $=\{$ Annual purchase volume $\} \times\{$ Sample percentage inbound quality check $\} \times\{$ Average time spent on checking one window $\} \times\{$ Labor cost per hour $\}$.

\section{- Supplier returns}

- Value of returns $=(\{$ Number of returns $\} \times\{$ Weighted average preferred price $\})$.

- Part of returns inventory $=\{$ Value of returns $\} /\{\Sigma$ (Value of returns) $\}$.

- Warehouse cost returns per supplier $=\{$ Part of returns inventory $\} \times\{$ Warehouse cost $\}$.

- Opportunity cost of supplier windows $=\{$ Value of the returns $\} \times(1-\{$ Refund rate $\})$.

- Labor cost of returns $=\{$ Number of people assigned to quality supplier returns $\} \times(\{$ Annual labor cost $\} /\{$ Annual working time $\} \times$ A Average time spent on returning one window $\} \times\{$ Number of windows returned $\}{ }^{8}$

\section{- Adverse buy}

- Number of WS/BG/RS not delivered $=\{1-$ Supplier performance WS/BG/RS $\} \times\{$ Annual purchase volume WS/BG/RS\}.

\footnotetext{
${ }^{6}$ The preferred supplier price is the expected price, as the supplier does not yet deliver the window.

${ }^{7}$ The time spent by Carglass on quality confirmation activities is a function of the number of times Carglass needs to perform the quality confirmation. The supplier can bring down the costs associated with quality confirmation by delivering high-quality copied windows ("first time right").

${ }^{8}$ The number of windows returned is a function of the quality and the delivery performance.
} 
- Adverse buy because of non-delivery $=\{$ Number of windows WS/BG/RS not delivered $\} \times\{$ Percentage bought from preferred/non-preferred/dealer $\} \times\{$ Purchase price preferred/non-preferred/dealer - Purchase price preferred supplier\}.

- Number of WS/BG/RS of low quality = \{Number broken/scratch A/inclusions A (WS/BG/RS) $\} /\{$ Number of windows checked $\} \times\{$ Total annual purchase volume $\}$.

- Adverse buy because of low quality $=\{$ Number of windows of low quality $\} \times\{$ Percentage bought from preferred/non-preferred/dealer $\} \times\{$ Purchase price preferred/non-preferred/dealer - Purchase price preferred supplier\}.

\section{- Warehousing}

\section{- Handling}

- Total number of crates $=\{$ Total annual purchase volume\}/\{Average number of windows per crate\}.

- Total number of dealer packages $=(\{$ Number of WS not delivered $\} \times\{$ Percentage bought again from dealer $\}+\{$ Number of BG not delivered $\} \times\{$ Percentage bought again from dealer $\}+\{$ Number of RS not delivered $\} \times\{$ Percentage bought again from dealer $\}+\{$ Number of windows of low quality $\} \times\{$ Percentage bought again from dealer\})/\{Average number of windows per dealer package\}.

- Total number of hours spent on crates/dealer packages $=\{$ Total number of crates/dealer packages $\} \times\{$ Time spent on crate/dealer packages\}.

- Labor cost of supplier windows/dealer windows $=\{$ Total number of hours spent on crates/dealer packages $\} \times\{$ Annual labor cost $\} /\{$ Annual working time $\}$.

\section{- Inventory holding}

- Cycle stock $=\{$ Purchase volume $\} \times\{$ Average ordering interval $\}$.

- Total annual inventory cost $=\{$ Cycle stock $\} \times\{$ Value per stock keeping unit $\} \times\{$ Interest rate $\}$.

- Safety stock $=\{k\} \times\{$ sd demand during leadtime $\}$, where sd demand during leadtime $=\sqrt{\left((\text { average leadtime })^{2} \times \sigma_{\text {demand }}^{2}+(\text { average demand })^{2} \times \sigma_{\text {leadtime }}^{2}\right)}$

\section{- Storing}

- Warehouse cost per supplier $=\{$ Cycle stock $\} /\{$ Maximum capacity of the warehouse $\} \times\{$ Warehouse cost $\}$.

\section{- Supplier monitoring}

- Total labor cost of supplier monitoring $=\{$ Number of people assigned to supplier monitoring $\} \times\{$ Labor cost $\} \times$ \{Percentage of labour spent on supplier monitoring $\}$.

- Labor cost supplier monitoring per supplier $=\{\text { Percentage of total supplier monitoring }\}^{9} \times\{$ Total labor cost of supplier monitoring\}.

\section{- Cashflow}

- Interest cost $=\{$ Interest rate $\} \times\{$ Total annual purchase value $\} \times(30-\{$ Payment term $\})$.

\footnotetext{
${ }^{9}$ The time spent on monitoring individual suppliers is a function of the delivery and the quality performance. It is difficult to develop a formula that approaches this function; however, Carglass can base the calculations on estimations of time spent (percent) on an individual supplier based on Carglass' historical experience and future expectations.
} 